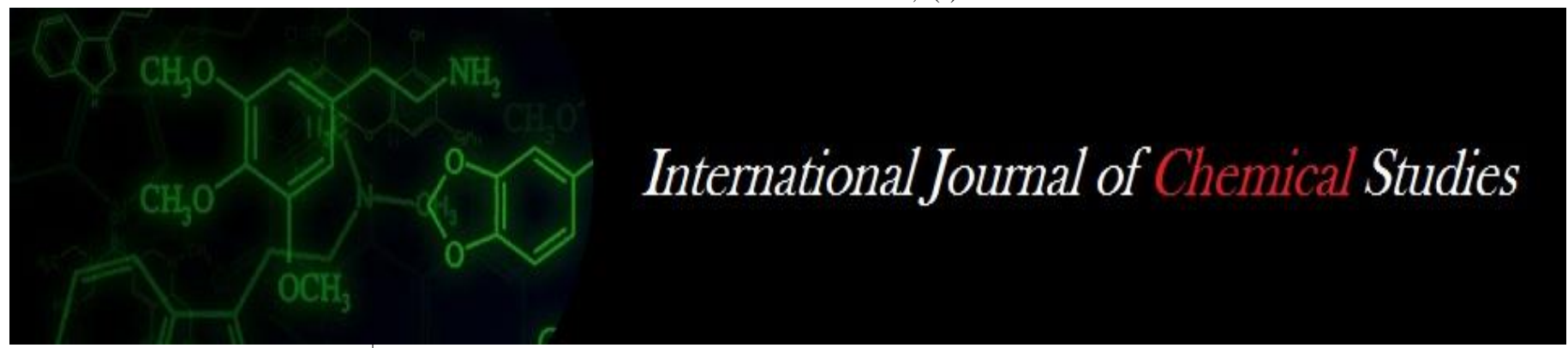

P-ISSN: 2349-8528

E-ISSN: 2321-4902

www.chemijournal.com

IJCS 2020; 8(4): 2444-2450

(C) 2020 IJCS

Received: 19-05-2020

Accepted: 21-06-2020

\section{SK Tiwari}

BRSM College of Agricultural

Engineering and Technology \&

Research Station Indira Gandhi

Agriculture University, Raipur,

Chhattisgarh, India
Corresponding Author:

\section{SK Tiwari}

BRSM College of Agricultural

Engineering and Technology \&

Research Station Indira Gandhi

Agriculture University, Raipur,

Chhattisgarh, India

\title{
Preparation of herbal soap by using guava \& neem leaves extract and study their properties \& applications
}

\section{SK Tiwari}

DOI: https://doi.org/10.22271/chemi.2020.v8.i4ab.10002

\section{Abstract}

Soaps are the sodium salts or potassium salts of stearic acids. They are prepared by the saponification process, which is, reacting the oil which contains triglycerides with Caustic soda $(\mathrm{NaOH})$ to give the soap. In the present work prepared total ten numbers of herbal soaps by using Guava and Neem leaves extract with 5 different types of oils (Coconut, Teel, Olive, Mustard and Sunflower). In this process used turmeric, indigo, milk powder, henna and coffee powder as a colouring agent and Lemon grass leaves extract as a flavouring agent. After preparation of soaps analyzed different properties of soap such as foaming capacity, yield percentage, lathering power, cleansing power, hardness and moisture content of samples. After analysis conclude that the soap prepared with Coconut oil is best among them and soap with Sunflower oil is poor quality. It has been also concluded that the soap prepared by guava leaf extract can be used for washing wounds.due to anti bacterial properties.

Keywords: Herbal soap, guava leaves, neem leaves, antibacterial properties

\section{Introduction}

Soap is sodium or potassium salt of fatty acid produced by saponification reaction using sodium or potassium hydroxide. Based on its chemical properties as an anionic surface active agent (surfactant), soap is used to clean and wash skin and clothing ${ }^{[1]}$. The fatty acids, stearic, palmitic, myristic, lauric and oleic acids, contribute to lathering and washing properties of the soaps ${ }^{[2]}$. Palm oil has been widely used as fatty raw material in the manufacture of soap ${ }^{[3]}$. The chemical characteristics of soap depend on several factors: the strength and purity of alkali, the kind of oil used, completeness of saponification and age of the soap. Such chemical characteristics include moisture content, total fatty acids (TFM), $\mathrm{pH}$, free alkali, and percent chloride ${ }^{[4]}$. Neem oil has been used in the manufacture of natural cosmetics, soap, toothpaste, hair and skin care products, emulsions, liquors, ointments and medicinal cosmetics [5]. However neem oil can be produced mechanically (hot or cold press) or chemically (solvent extraction) from dried neem seeds. The best quality neem oil with a majority of phytoconstituents intact is obtained through cold press. In cold press the oil is lighter in colour and has a milder odour ${ }^{[6]}$. Moreover potential residual solvents in chemical extracted oil that may pose health hazards to consumers are eliminated since solvents are not used in the pressing techniques. Neem oil contains polysaccharides and limonoids that reduce tumors and cancers eg lymphocytic leukemia and skin cancers ${ }^{[7]}$. Some of the limonoid compounds are azadirachtin, salannin, meliantriol, nimbin and nimbidin desacetylnimbin, Azadiradione, Azadirone, Nimbolin, Nimbinene, Nimbolide ${ }^{[8]}$. The phenolic compounds containg catechin reduces inflammation, pain and swelling that occur in arthritis ${ }^{[9]}$. Neem oil combats vaginal infections and sexually transmitted diseases, kills lice ${ }^{[10]}$, scabies ${ }^{[11]}$, ringworm, athlete's foot fungus ${ }^{[12]}$ and Phytophthora infestans, repels mosquitoes, fleas and houseflies when applied to the skin ${ }^{[13]}$ and solves the problem of dandruff, baldness and graying of hair ${ }^{[14]}$. It cures leprosy, rheumatism, chronic syphilitic sores and indolent ulcer. It clears gonorrhoeae, herpes simplex-2, HIV-1, resistant strains of E. coli, Staphylococcus aureus, chicken pox ${ }^{[15]}$, cholera, pneumonia, tuberculosis, peptic ulcer, diabetic foot, dry psoriasis and heals wound and other skin disorders ${ }^{[16]}$.

I have selected the work on the preparation of herbal soap by using guava and neem leaves extract and different oil because to till date this work has not been done by any researcher. 
Therefore, the purpose of this work is to use guava and neem leaves extract as a cheap source of fatty material and have antibacterial properties.

\section{Material and Method}

Table 1: All the five varieties of soap making oils were purchases from the local market.

\begin{tabular}{|l|l|l|}
\hline Type of soap making oil used & Brand name & Cost Rupees/100ml \\
\hline
\end{tabular}

\begin{tabular}{|c|c|c|}
\hline Coconut oil & parachute & 23 \\
\hline Teel oil & vanaraj & 41 \\
\hline Olive oil & figaro & 104 \\
\hline Mustered Oil & Lal gulab & 10 \\
\hline Sunflower oil & Sunbeam & 12 \\
\hline
\end{tabular}

2.1 Colouring agent: The following colouring agent were collected from local farmer and purchases from the local market.

(a) Milk-: White colour (b) Turmeric-: Yellow to orange colour (c) Coffee powder-: Brown black colour (d) Henna leaf-: Brown colour (e) Indico powder-: Blue colour.

2.2 Flavouring Agent: Lemon grass has collected from IGKV campus Raipur.

\subsection{Methodology:}

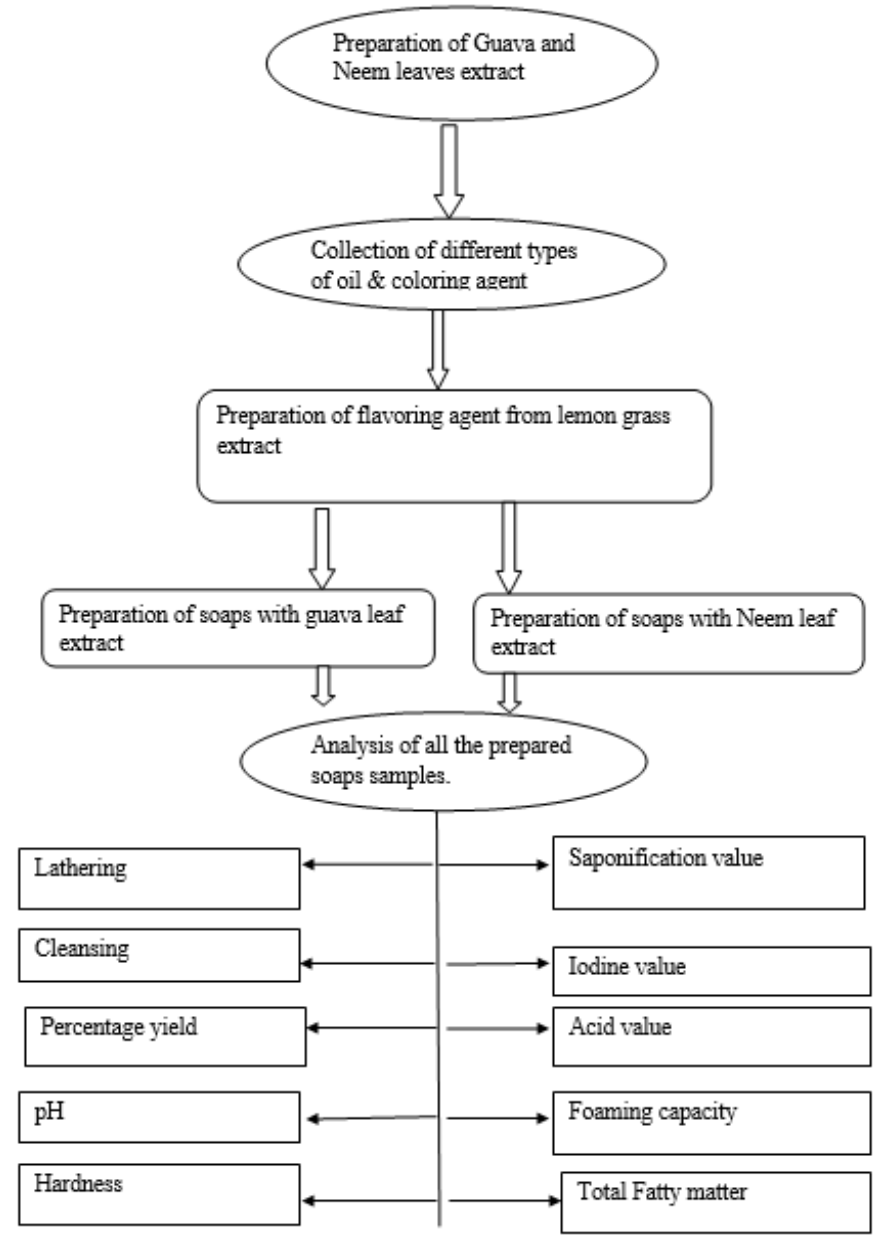

The only reagent used in herbal soap making was Caustic soda which has purchases from kasliwall brother, Raipur. Five different types of coloring agent turmeric, indigo, henna, coffee and milk powder also has been purchased from local market (super-market) Mungeli. We have prepared lemon grass extract for flavoring agent.
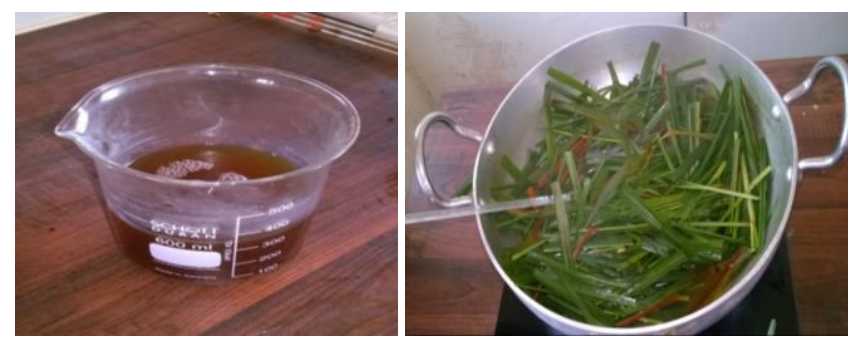

Fig 1: Lemon grass and prepared lemon grass extract used as a flavoring agent.

\subsection{Preparation of soap}

Total 10 numbers of soap samples were prepared. Five samples has prepared by using Guava leaves extract with different oil and colouring agent and Five samples has prepared by using Neem leaves extract with different oil and colouring agent.

\subsubsection{Preparation of Soap by using guava leaf extract}

Firstly leaves extract was prepared by boiling the leaves. We have to gather $100 \mathrm{gm}$ of fresh green guava leaves, $500 \mathrm{ml}$ of Water and boil it for about 30 minutes. After preparation it filters and collected in fresh beaker. Now $500 \mathrm{ml}$ of distill water is boiled with $25 \mathrm{ml}$ of coconut oil for 30 minutes. Now $250 \mathrm{ml}$ of guava leaf extract was added in it. It was again heated for 30 minutes. Now 6 gm of caustic soda $(\mathrm{NaOH})$ was weighed in weighing machine. The same amount of caustic soda was added in the solution with continuous stirring with the help of stirring rod. Now addition of $2 \mathrm{gm}$ of coloring agent's turmeric powder and $50 \mathrm{ml}$ of lemon grass leaf extract. Now Continuous stirring is done till the solution concentrates. When the solution concentrates then it is poured in the beaker. Now placed in a safe area that cannot expose by sun and Cut the soap according to the size of moulder. Similarly we have prepared another four numbers of soaps samples with four different oil \& colouring agents such as mustard, olive, Teel and sunflower oil and henna, milk, coffee \& indigo powder.
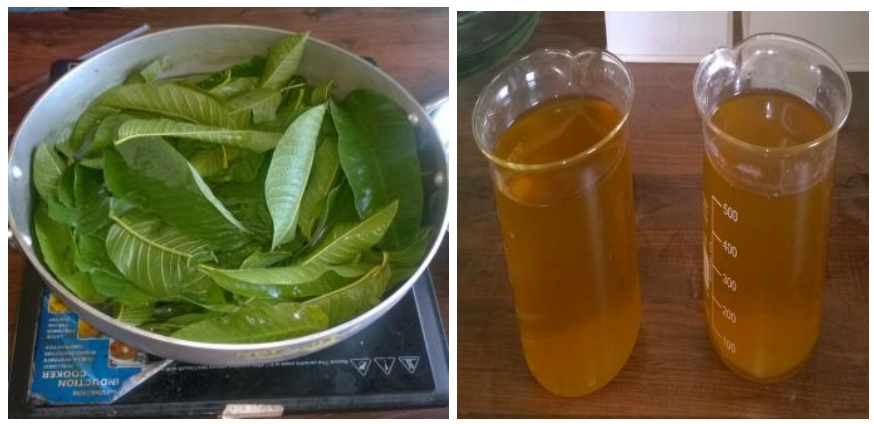

Fig 2: Fresh Guava leaves and prepared Guava leaves extract.

\subsubsection{Preparation of Soap by using Neem leaf extract}
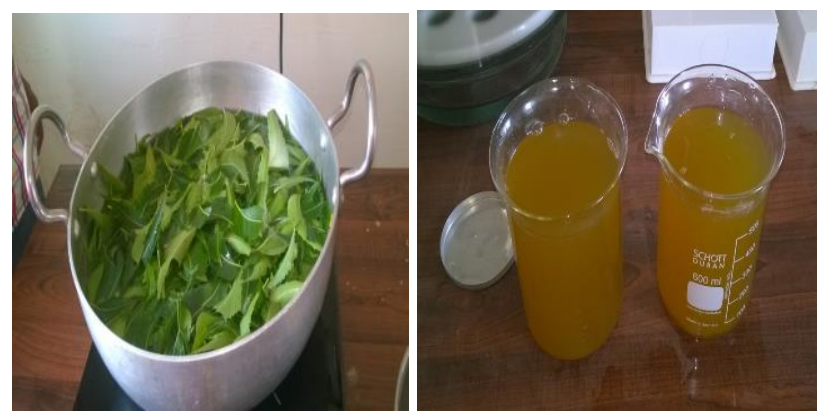

Fig 3: Fresh Neem leaves and prepared Neem leaves extract 
Firstly leaves extract was prepared by boiling the leaves. We have to gather $100 \mathrm{gm}$ of fresh green Neem leaves, $500 \mathrm{ml}$ of Water and boil it for about 30 minutes. After preparation it filters and collected in fresh beaker. Now $500 \mathrm{ml}$ of distill water is boiled with $25 \mathrm{ml}$ of coconut oil for 30 minutes. Now $250 \mathrm{ml}$ of Neem leaf extract was added in it. It was again heated for 30 minutes. Now $6 \mathrm{gm}$ of caustic soda $(\mathrm{NaOH})$ was weighed in weighing machine. The same amount of caustic soda was added in the solution with continuous stirring with the help of stirring rod. Now addition of $2 \mathrm{gm}$ of coloring agent's turmeric powder and $50 \mathrm{ml}$ of lemon grass leaf extract. Now Continuous stirring is done till the solution concentrates. When the solution concentrates then it is poured in the beaker. Now placed in a safe area that cannot expose by sun and Cut the soap according to the size of moulder. Similarly we have prepared another four numbers of soaps samples with four different oil \& colouring agents such as mustard, olive, Teel and sunflower oil and henna, milk, coffee \& indigo powder.

\subsection{Analysis of soap}

After preparation of soaps samples we have study different properties of prepared soaps such as percentage yield, moisture content, $\mathrm{pH}$ value, foaming capacity, saponification value etc.

\subsubsection{Calculation of percentage Yield:}

Percentage yield of all the soap samples has been calculated. For this at first we have taken weight of soap sample before drying, then weight of soap sample after drying seven day. Percentage yield has been calculated by dividing the weight of the soap after drying to the weight of the soap samples before drying with multiplied by 100 . It has calculated for all the samples. i.e

Weight of soap after seven days drying $\times 100$

$$
\text { Weight of soap before drying }
$$

\subsubsection{Determination of $\mathrm{pH}$}

Two grams of the powdered soap sample was weighed and dissolved in $20 \mathrm{ml}$ distilled water in a $100 \mathrm{ml}$ volumetric flask. This was made up to prepare $10 \%$ soap solution. The $\mathrm{pH}$ was determined by using $\mathrm{pH}$ meter (Digital ESICO $\mathrm{pH}$ Meter, Model 1012) which is available in chemistry laboratory in the college.

\subsubsection{Calculation of Cleansing Power}

A drop of used brake oil was placed on four separate thin strips of filter paper. It is made sure that the strips of filter paper will fit in the test tubes used in the previous step. One filter paper with oil spot in the tube containing soap in water. Another is placed in the tube containing detergent and water. A third strip is placed in the tube containing soap in calcium solution. The fourth strip of oily paper was placed in the tube containing detergent and calcium solution. Each one is shaken well and made sure that the filter paper is immersed in the solution. After 2 min the filter paper was removed and rinsed with tap water. Did the oil get washed out of the filter paper strip? The solutions were thrown in the sink. The paper strips were thrown in the trash can. The cleaning power of soap versus detergent was compared. This reaction was carried out for all the five samples prepared

\subsubsection{Analysis of moisture Content}

Moisture content is the important properties of soaps and it has calculated by following methods. Approximately $5 \mathrm{~g}$ of soap samples was accurately weighed using analytical balance (sensitivity $0.1 \mathrm{mg}$ ) into dried, tarred moisture dish and dried in an oven (Memmert, Germany) for $2 \mathrm{hr}$ at $100 \pm 1{ }^{\circ} \mathrm{C}$ and repeated until a constant weight (difference between two measurement not exceed $0.5 \mathrm{mg} / \mathrm{g}$ of sample) was reached. The $\%$ moisture was calculated using the following formula.

$\frac{\mathrm{Cs}-\mathrm{Ch} \times 100}{\mathrm{Cs}-\mathrm{Cw}}$

Where

$\mathrm{C}_{\mathrm{w}}=$ weight of crucible, $\mathrm{C}_{\mathrm{s}}=$ weight of crucible + sample.

$\mathrm{C}_{\mathrm{h}}=$ weight of crucible + sample after heating

\subsubsection{Determination of Hardness:}

The hand felt hardness was determined relatively to each other for all the soap samples. The properties of the soap were tabulated and compared with each other. But the primary objective of this work is to compare their properties.

Similarly by using standard methods we have calculated total Fatty Matter, Saponification Number and Acid value of prepared soaps.

\subsubsection{Calculation of Foaming Capacity of Soaps}

Five conical flasks $(100 \mathrm{ml}$ each) are taken and numbered 1 to 5. In each of these flasks equal amounts (say $5 \mathrm{gm}$ ) of the given samples of soap shavings or granules are taken and 50 $\mathrm{ml}$ of distilled water is added. Each conical flask is heated few minutes to dissolve all the soap completely. In a test-tube stand, five big clean and dry test tubes are taken and numbered 1 to 5 , One $\mathrm{ml}$ of the five soap solution is then poured in the test tubes of corresponding number. $10 \mathrm{ml}$. of distilled water is then added to each test tube. Test tube no 1 is then shaken vigorously 5 times. The foam would be formed in the empty space above the container. Stop watch is started immediately and the time taken for the disappearance of foam is noted. Similarly the other test tubes are shaken vigorously for equal number of times (i.e., 5 times) with approximately with the same force and the time taken for the disappearance of foam in each case is recorded. The lesser the time taken for the disappearance of foam, the lower is the foaming capacity. The soap for which the time taken for the disappearance of foam is highest has maximum foaming capacity and is the best quality soap among the soaps tested.

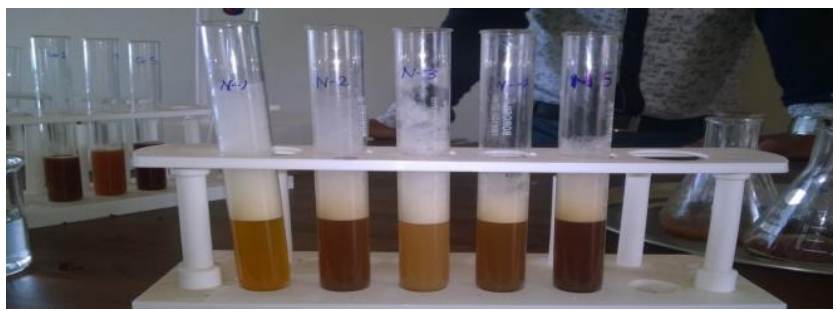

Fig 4: Showing the determination of foaming capacity of different prepared soap sample.

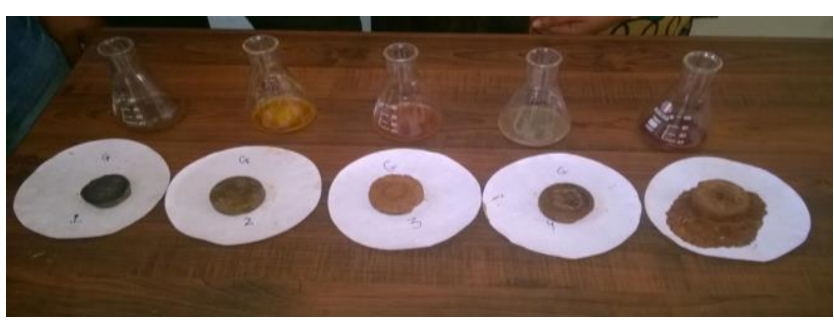

Fig 5: Showing the prepared guava leaves extract soap and their liquid form for analysis 


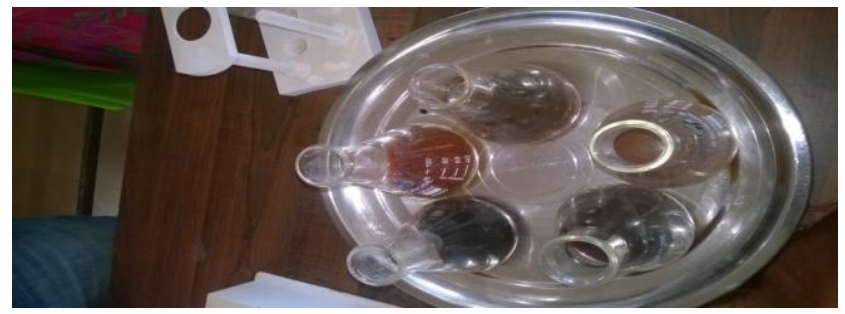

Fig 6: Showing the prepared Neem leaves extract soap and their liquid form for analysis

\section{Result and discussion}

\subsection{Percentage of Yield}

Higher the yield is more economical is the Process of soap making. From above studied it is found that the soap prepared by coconut oil gives high percentage yield as compare to soap with Teel oil and Olive oil and soap prepared with mustered and Sunflower oil is lower percentage yield (shown in table 3.1 and 3.2). If we compare the soap prepared by Guava leaf extract and Neem leaf extract than found that the Guava leaf extract soap with coconut oil is high percentage yield as compare to Neem leaf extract with coconut oil and in both cases the soap with sunflower oil is lower percentage yield shown in figure 3.1

Table 3.1: Yield of Guava leaf extract soap using individual oils.

\begin{tabular}{|c|c|c|c|}
\hline $\begin{array}{c}\text { Type of soap } \\
\text { making oil used }\end{array}$ & $\begin{array}{c}\text { Weight of soap } \\
\text { before drying }\end{array}$ & $\begin{array}{c}\text { Weight of soap } \\
\text { after drying }\end{array}$ & Yield (\%) \\
\hline Coconut oil $\left(\mathrm{G}_{1}\right)$ & 25.8 & 25.3 & $98 \%$ \\
\hline Teel oil $\left(\mathrm{G}_{2}\right)$ & 26.5 & 25.2 & $95 \%$ \\
\hline Olive oil $\left(\mathrm{G}_{3}\right)$ & 25.3 & 20.5 & $81 \%$ \\
\hline Mustered Oil $\left(\mathrm{G}_{4}\right)$ & 25.1 & 18.2 & $72.8 \%$ \\
\hline Sunflower oil $\left(\mathrm{G}_{5}\right)$ & 26.3 & 16.5 & $62.7 \%$ \\
\hline
\end{tabular}

Table 3.2: Yield of Neem leaf extract soap using individual oils.

\begin{tabular}{|c|c|c|c|}
\hline $\begin{array}{c}\text { Type of soap } \\
\text { making oil used }\end{array}$ & $\begin{array}{c}\text { Weight of soap } \\
\text { Before drying }\end{array}$ & $\begin{array}{c}\text { Weight of soap } \\
\text { after drying }\end{array}$ & Yield (\%) \\
\hline Coconut oil $\left(\mathrm{N}_{1}\right)$ & 26.5 & 24.4 & $92 \%$ \\
\hline Teel oil $\left(\mathrm{N}_{2}\right)$ & 26.2 & 22.3 & $85 \%$ \\
\hline Olive oil $\left(\mathrm{N}_{3}\right)$ & 25.2 & 19.2 & $76 \%$ \\
\hline Mustered Oil $\left(\mathrm{N}_{4}\right)$ & 24.8 & 16.9 & $68 \%$ \\
\hline Sunflower oil $\left(\mathrm{N}_{5}\right)$ & 25.3 & 15.2 & $60 \%$ \\
\hline
\end{tabular}

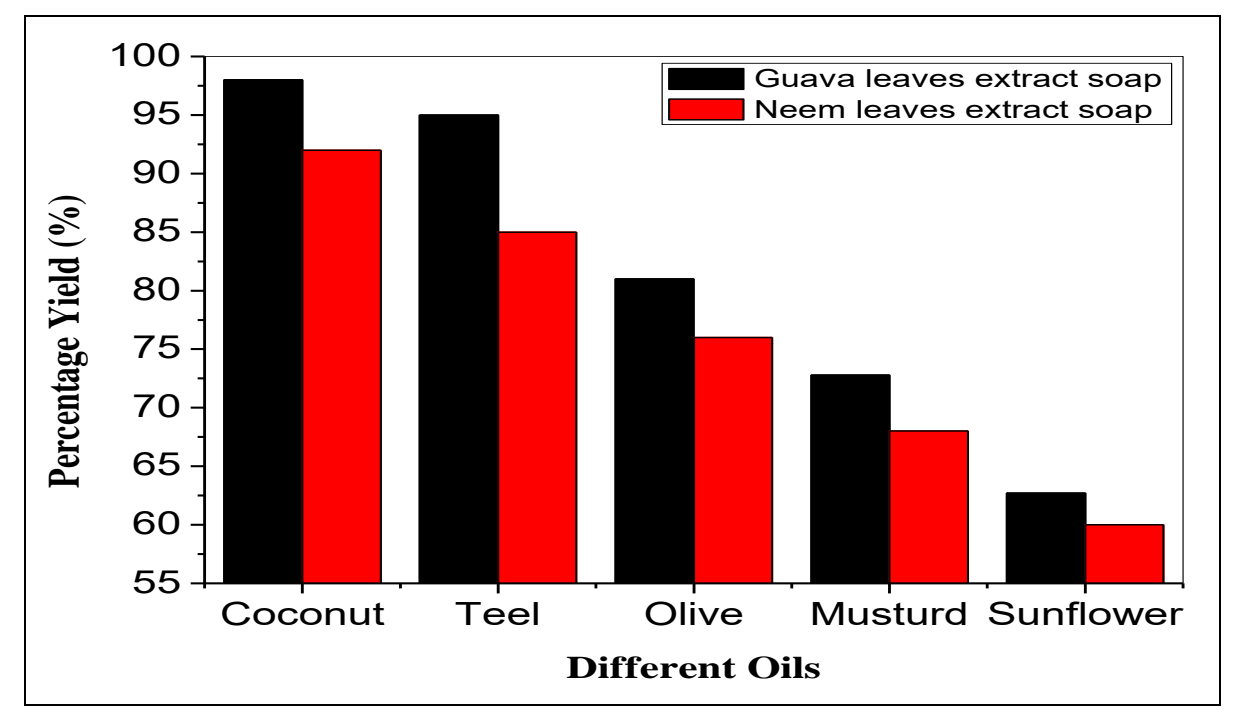

Fig 3.1 Percentage yield between soaps prepared by guava and Neem leaves extract.

\section{$3.2 \mathrm{pH}$ value, lathering power and Cleansing power}

From studied it is found that the soap prepared by coconut oil has lower $\mathrm{pH}$ value as compare to soap with Teel oil and Olive oil and soap prepared with mustered and Sunflower oil has higher $\mathrm{pH}$ value which is shown in table 3.3 and 3.4. The soap with coconut oil is higher Lathering and Cleansing power and soap with sunflower oil is poor Lathering and Cleansing power and the soap prepared by Guava leaf extrac has lower $\mathrm{pH}$ value and higher Lathering and Cleansing power as compare to soap prepared by Neem leaf extract. If we compare the $\mathrm{pH}$ value of soap prepared by Guava leaf extract and Neem leaf extract than found that the Guava leaf extract soap with coconut oil is lower $\mathrm{pH}$ value as compare to Neem leaf extract with coconut oil similarly teel oil containing guava leaves soap has lower pHas compare to neem leaves soap and in both cases the soap with sunflower oil is lower is higher $\mathrm{pH}$ value which is shown in figure 3.2.

Table 3.3: $\mathrm{pH}$ value, lathering power and Cleansing power of Guava leaf extract soap

\begin{tabular}{|c|c|c|c|}
\hline $\begin{array}{c}\text { Type of soap making oil } \\
\text { used }\end{array}$ & $\begin{array}{c}\text { pH of } \\
\text { soap }\end{array}$ & $\begin{array}{c}\text { Lathering } \\
\text { power }\end{array}$ & $\begin{array}{c}\text { Cleansing } \\
\text { power }\end{array}$ \\
\hline Coconut oil & 9.0 & Very High & Very High \\
\hline Till oil & 9.2 & High & High \\
\hline Olive oil & 9.75 & Good & Good \\
\hline Mustered Oil & 9.82 & lower & lower \\
\hline Sunflower oil & 10.0 & Poor & Poor \\
\hline
\end{tabular}

Table 3.4: $\mathrm{pH}$ value, lathering power and Cleansing power of Neem leaf extract soap.

\begin{tabular}{|c|c|c|c|}
\hline Type of soap making oil used & pH of Soap & Lathering power & Cleansing power \\
\hline Coconut oil (N1) & 9.2 & Very High & Very High \\
\hline Teel oil (N2) & 9.3 & High & High \\
\hline Olive oil (N3) & 9.8 & Good & Good \\
\hline Mustered Oil (N4) & 9.9 & lower & lower \\
\hline Sunflower oil (N5) & 10.3 & Poor & Poor \\
\hline
\end{tabular}




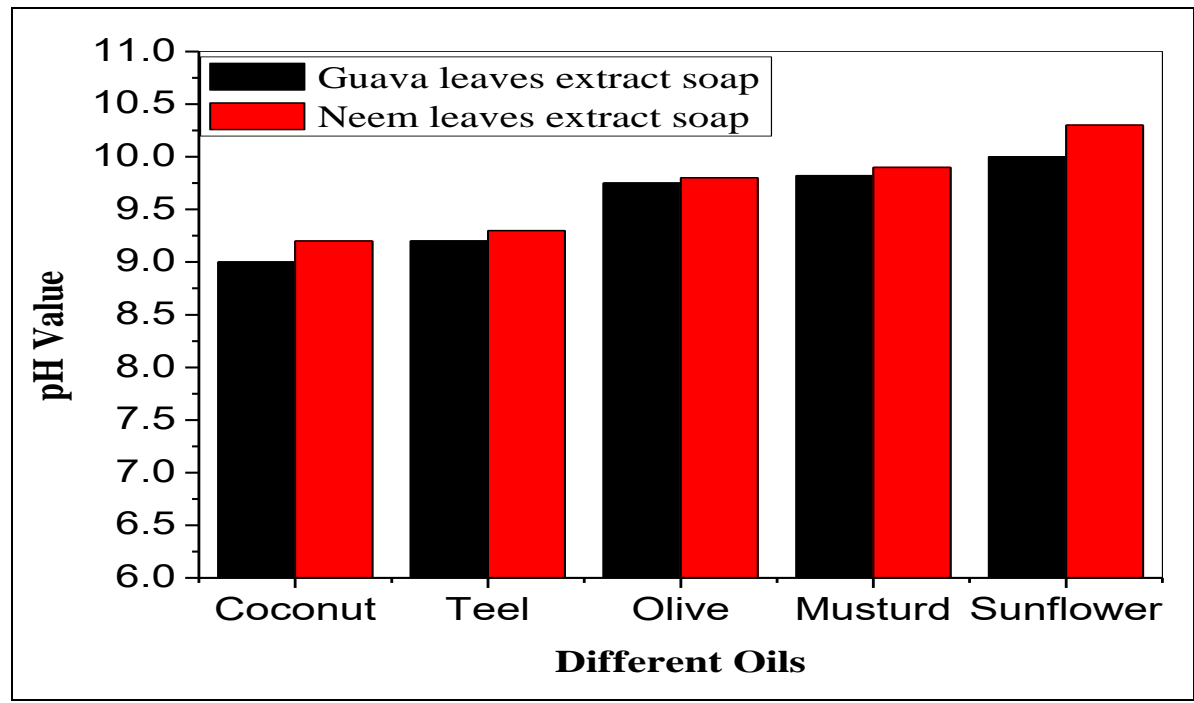

Fig 3.2: Caparison of $\mathrm{pH}$ value between soaps prepared by guava and Neem leaves extract.

\subsection{Moisture content and Hardness}

Table 3.5: Moisture and Hardness of Guava leaf extract soap using individual oils.

\begin{tabular}{|c|c|c|}
\hline Type of soap making oil & Moisture Content (\%) & Hardness \\
\hline Coconut oil & 6.39 & Soft \\
\hline Teel oil & 6.19 & Soft \\
\hline Olive oil & 5.98 & Soft \\
\hline Mustered Oil & 5.45 & hard \\
\hline Sunflower oil & 5.22 & hard \\
\hline
\end{tabular}

From above studied it is found that the soap prepared by coconut oil has high percentage of moisture content as compare to soap with Teel oil and Olive oil and soap prepared with mustered and Sunflower oil has lower percentage of moisture content.

Table 3.6: Moisture and Hardness of Neem leaf extract soap using individual oils

\begin{tabular}{|c|c|c|}
\hline Type of soap making oil & Moisture Content (\%) & Hardness \\
\hline Coconut oil & 6.1 & Soft \\
\hline Till oil & 5.8 & Soft \\
\hline Olive oil & 5.6 & Slightly hard \\
\hline Mustered Oil & 4.47 & hard \\
\hline Sunflower oil & 3.42 & hard \\
\hline
\end{tabular}

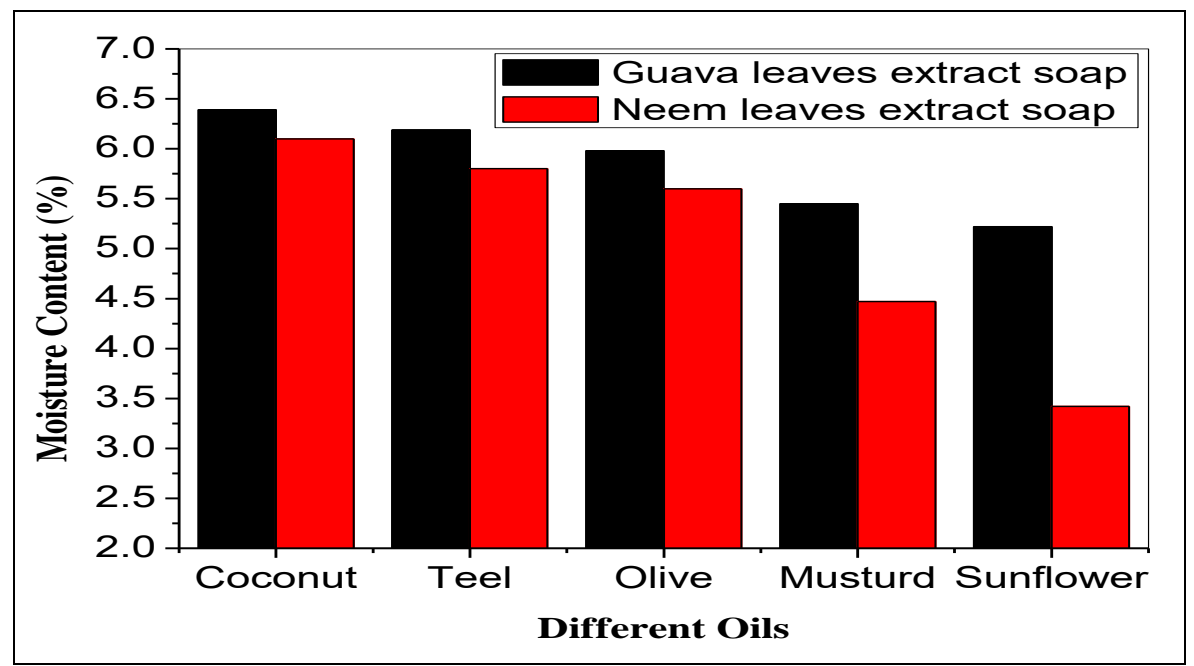

Fig 3.3: Caparison of moisture content between soaps prepared by guava and Neem leaves extract

If we compare the soap prepared by Guava leaf extract and Neem leaf extract than found that the Guava leaf extract soap with coconut oil is high percentage of moisture content as compare to Neem leaf extract with coconut oil and in both cases the soap with sunflower oil is low percentage of moisture content. Therefore soap with coconut oil is soft and soap with sunflower oil is hard and the soap prepared by Guava leaf extract has more softened as compare to soap prepared by Neem leaf extract which is shown in figure 3.3.

\subsection{Foaming capacity}

From studied it is found that the soap prepared by coconut oil has high value of foaming capacity as compare to soap with Teel oil and Olive oil and soap prepared with mustered and Sunflower oil has lower value of Foaming capacity which is shown in table 3.7 and Figure 3.4. 
Table 3.7: Foaming capacity of Guava leaf extract soap using individual oils

\begin{tabular}{|c|c|c|}
\hline Soap making oil used & Guava leaf extract soap & Neem leaf extract soap \\
\hline Coconut oil $\left(\mathrm{G}_{1}\right)$ & 22 minutes & 19 minutes \\
\hline Teel oil $\left(\mathrm{G}_{2}\right)$ & 20 minutes & 17 minutes \\
\hline Olive oil $\left(\mathrm{G}_{3}\right)$ & 14 minutes & 11 minutes \\
\hline Mustered Oil $\left(\mathrm{G}_{4}\right)$ & 9 minutes & 8.6 minutes \\
\hline Sunflower oil $\left(\mathrm{G}_{5}\right)$ & 4.5 minutes & 4.3 minutes \\
\hline
\end{tabular}

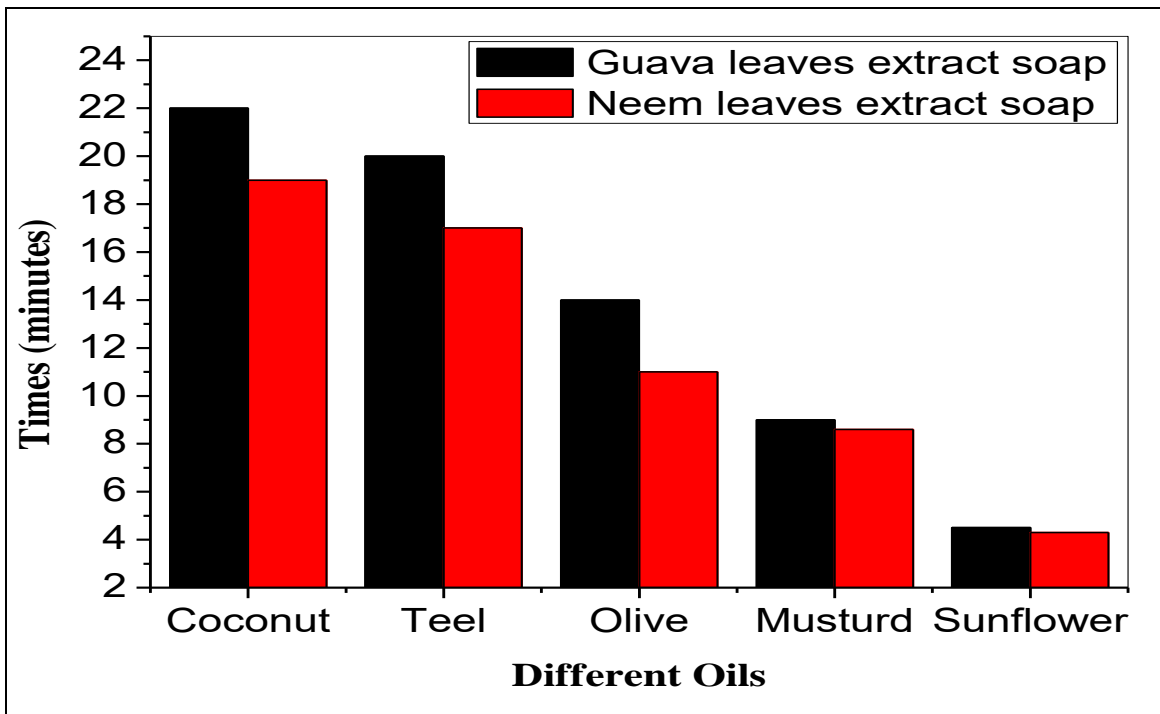

Fig 3.4: Caparison of Foaming capacity between soaps prepared by guava and Neem leaves extract

\section{Conclusion}

Soap was prepared using Guava leaf extract and Neem leaf extract with five different oil such as coconut oil, Teel oil, Olive, mustard and sunflower oil. In this process we used Turmeric, Indigo, henna, Coffee and milk powder as a coloring agent and lemon grass extract as a flavoring agent. Total ten numbers of soap samples were prepared. The soap was tested for various properties and compared all properties between guava leaf extract soap with Neem leaf extract soap. All necessary properties like percentage yield, Lathering power, Cleansing power, $\mathrm{pH}$, Hardness, and Moisture were studied to select the best leaf extract out of two and oil out of all the five oil. The best leaf extract guava was found out of two and to be coconut oil. We were also studied foaming capacity of all prepared and conclude that:-

- Soap prepared by coconut oil gives high percentage yield $(98 \%)$ as compare to soap with Teel oil (95\%), Olive oil $(81 \%)$, mustered oil $(72.8 \%)$ and Sunflower oil $(62.7 \%)$ is lower percentage yield.

- The Guava leaf extract soap with coconut oil is high percentage yield (98\%) as compare to Neem leaf extract with coconut oil (92\%) and in both cases the soap with sunflower oil is lower percentage yield.

- The soap prepared by coconut oil has lower $\mathrm{pH}$ value as compare to soap with Teel and Olive oil while soap with mustered and Sunflower oil has higher $\mathrm{pH}$ value.

- Guava leaf extract soap with coconut oil is lower $\mathrm{pH}$ value as compare to Neem leaf extract with coconut oil and in both cases the soap with sunflower oil is lower is higher $\mathrm{pH}$ value.

- The soap prepared by guava leaf extract with coconut oil is higher Lathering and Cleansing power and soap with sunflower oil is poor Lathering and Cleansing power.

- Soap prepared by Guava leaf extract has higher Lathering and Cleansing power as compare to soap prepared by Neem leaf extract.
- It was also observed that the coconut oil soap has high percentage of moisture content so it is soft as compare to soap with Teel oil and Olive oil and soap prepared with mustered and Sunflower oil has lower percentage of moisture content.

- The Guava leaf extract soap with coconut oil is high percentage of moisture content as compare to Neem leaf extract with coconut oil and in both cases the soap with sunflower oil is low percentage of moisture content.

- Therefore soap with coconut oil is soft and soap with sunflower oil is hard and the soap prepared by Guava leaf extract has more softened as compare to soap prepared by Neem leaf extract.

- Guava leaf extract soap with coconut oil is high value of Foaming capacity as compare to Neem leaf extract with coconut oil and in both cases the soap with sunflower oil is lower value of Foaming capacity.

\section{References}

1. Mak-Mensah EEE, Firempong CK. Chemical characteristics of toilet soap prepared from neem (Azadirachta indica A. Juss) seed oil. Asian Journal of Plant Science and Research, 2011; 1(4):1-7.

2. Ainie K, Hamirin K, Peang-Kean L. J. Am. Oil Chem. Soc., 1996; 73:105-108.

3. Ahmed I. Palm Oil research Institute of Malaysia (PORIM), Selangor, Malaysia, 1984, 1-17.

4. Girgis AY. Grasas y Aceites, 2003; 54(3):226-233.

5. Chatterjee A, Pakrashi S. Treatise on Indian Medicinal Plants. Publications and Directorate, New Delhi, 1994; 3:73.

6. Ramakrishna G, Prasad NBL, Azeemoddin G, Cold processing neem seed, JNTU, Oil Technological Research Institute, Proceedings of the World Neem Conference, Bangalore, India, 1993, 24-28.

7. Sai Ram M, Sharma SK, Ilavazhagan G, Kumar D, Selvamurthy W, J Ethnopharmacol. 1997; 55(2):133-139. 
8. Sadekar RD, Kolte AY, Barmase BS, Desai VF, Indian J. Exp. Biol. 1998; 36:1151-1153.

9. Subapriya R, Nagini S. Curr. Med. Chem. Anticancer Agents. 2005; 5(2):149-156.

10. Abdel-Ghaffar F, Semmler M. Parasitol. Res., 2007; 100(2):329-332.

11. Heukelbach J, Feldmeier H. Lancet, 2006; 367:17671774.

12. Khan M, Wassilew SW. Natural Pesticides from the Neem Tree and Other Tropical Plants (eds Schmutterer, H. and Asher, K. R. S.), GTZ. Eschborn Germany, 1987; 645-650.

13. http://www.herbalremediesinfo.com/teatree-neemoregano.html.

14. http://www.vpnutrition.com/pdf/1564 Neem.pdf.

15. Talwar GP, Shah S, Mukherjee S, Chabra R. Am. J. Reprod. Immunol, 1997; 37(6):485-91.

16. Schmutterer $\mathrm{H}$, The neem tree Azadirachta indica (A. Juss.) and other meliaceous plants: sources of unique natural products for integrated pest management, medicine, industry and other purposes, VCH Publishers Inc., New York, 1995, 2-7, 39-56, 71, 519-523.

17. Debesh Mishra, M. Tech. Thesis, Preparation of Soap Using Different Types of Oils and Exploring its Properties, 2009. 